\title{
Establishing the Appropriate Conditions of Regeneration of Cataytic Reforming $\mathrm{Pt} / \mathrm{AL}_{2} \mathrm{O}_{3}$ Catalyst
}

\author{
Paul Chidi Okonkwo*, Benjamin Aderemi, Taiwo Olamide Olori \\ Chemical Engineering Department, Faculty of Engineering Ahmadu Bello University, Zaria, Nigeria
}

Email address:

chemstprom@yahoo.com (P. C. Okonkwo)

${ }^{*}$ Corresponding author

To cite this article:

Paul Chidi Okonkwo, Benjamin Aderemi, Taiwo Olamide Olori. Establishing the Appropriate Conditions of Regeneration of Cataytic Reforming Pt/AL $\mathrm{O}_{3}$ Catalyst. American Journal of Chemical Engineering. Vol. 5, No. 5, 2017, pp. 98-110. doi: 10.11648/j.ajche.20170505.12

Received: July 30, 2017; Accepted: August 18, 2017; Published: November 2, 2017

\begin{abstract}
Catalyst deactivation, the loss over time of catalytic activity and selectivity is a problem of great and continuing concern in the practice of industrial catalytic processes. Catalyst regeneration procedures for fixed-bed reforming units can vary widely. While all regeneration procedures share common elements, it is very common for the procedures to have evolved over years as unit configurations and throughputs have changed. Sub-optimal regeneration procedures can have a number of negative impacts on subsequent operation. In this study two samples of catalytic reforming $\mathrm{Pt} / \mathrm{Al}_{2} \mathrm{O}_{3}$ catalysts were obtained from operating fixed bed semi regenerative reactors which has run for 10,000 and 14000 hours. These samples which have undergone deactivation in the course of the operations were regenerated under varying conditions of temperature, pressure and chlorination to establish the appropriate regeneration conditions. The progress and extent of regeneration were monitored using FTIR, SEM, XRD, GC-MS and XRF. The carbon content and effectiveness of the regenerated catalysts were determined and the values were compared with that of fresh catalysts. The regenerated catalysts showed $98-99.5 \%$ of the catalyst activity under the conditions of temperature and pressure of $500^{\circ} \mathrm{C}$ and $15 \mathrm{psi}$ respectively. The established conditions are to guide economic operations of such units which to realize high quality reformates and long life of the catalysts.
\end{abstract}

Keywords: Catalytic Reforming, Deactivation, Regeneration, Catalyst Effectiveness, Catalyst Activity

\section{Introduction}

Catalytic reforming is a chemical process used to convert petroleum refinery naphthas distilled from crude oil (typically having low octane ratings) into high-octane liquid products called reformates, which are premium blending stocks for high-octane gasoline [1]. The process converts low-octane linear hydrocarbons (paraffins) into branched alkanes (isoparaffins) and cyclic naphthenes, which are then partially dehydrogenated to produce high-octane aromatic hydrocarbons. The dehydrogenation also produces significant amounts of byproduct hydrogen gas, which is fed into other refinery processes such as hydrocracking. A side reaction is hydrogenolysis, which produces light hydrocarbons of lower value, such as methane, ethane, propane and butanes. It is also the conversion of straight chains of alkane catalytically [2].
In addition to a gasoline blending stock, reformate is the main source of aromatic bulk chemicals such as benzene, toluene, xylene and ethylbenzene which have diverse uses, most importantly as raw materials for conversion into plastics. However, the benzene content of reformate makes it carcinogenic, which has led to governmental regulations effectively requiring further processing to reduce its benzene content.

There are many chemical reactions that occur in the catalytic reforming process, all of which occur in the presence of a catalyst and a high partial pressure of hydrogen. Depending upon the type or version of catalytic reforming used as well as the desired reaction severity, the reaction conditions range from temperatures of about 495 to $525^{\circ} \mathrm{C}$ and from pressures of about 5 to 45 atm [3]. The commonly used catalytic reforming catalysts contain noble metals such as platinum and/or rhenium, which are very susceptible to poisoning by sulfur and nitrogen compounds. 
Therefore, the naphtha feedstock to a catalytic reformer is always pre-processed in a hydrodesulfurization unit which removes both the sulfur and the nitrogen compounds. Most catalysts require both sulphur and nitrogen content to be lower than $1 \mathrm{ppm}$.

Most catalytic reforming catalysts contain platinum or rhenium on a silica or silica-alumina support base, and some contain both platinum and rhenium. Fresh catalyst is chlorided (chlorinated) prior to use.

The noble metals (platinum and rhenium) are considered to be catalytic sites for the dehydrogenation reactions and the chlorinated alumina provides the acid sites needed for Isomerization, cyclization and hydrocracking reactions [4]. The biggest care has to be exercised during the chlorination. Indeed, if not chlorinated (or insufficiently chlorinated) the platinum and rhenium in the catalyst would be reduced almost immediately to metallic state by the hydrogen in the vapour phase. On the other an excessive chlorination could depress excessively the activity of the catalyst The activity (i.e., effectiveness) of the catalyst in a semi-regenerative catalytic reformer is reduced over time during operation by carbonaceous coke deposition and chloride loss. The activity of the catalyst can be periodically regenerated or restored by in situ high temperature oxidation of the coke followed by chlorination. As stated earlier herein, semi-regenerative catalytic reformers are regenerated about once per 6 to 24 months.. The higher the severity of the reacting conditions (temperature), the higher is the octane of the produced reformate but also the shorter will be the duration of the cycle between two regenerations. Catalyst's cycle duration is also very dependent on the quality of the feedstock. However, independently of the crude oil used in the refinery, all catalysts require a maximum final boiling point of the naphtha feedstock of $180^{\circ} \mathrm{C}$ [5]. Performance of the catalyst decreases with respect to time due to deactivation. Deactivation can occur by a number of different mechanisms, both chemical and physical in nature. These are commonly divided into classes, namely coke formation or fouling, poisoning, sintering contamination on active sites and agglomeration. Other mechanisms of deactivation include masking and loss of the active elements via volatilization, erosion and attrition [6]. For catalytic reactions involving hydrocarbons (or even carbon oxides) side reactions occur on the catalyst surface leading to the formation of carbonaceous residues (usually referred to as coke or carbon) which tend to physically cover the active surface. Coke deposits may amount to $15 \%$ or even $20 \%(\mathrm{w} / \mathrm{w})$ of the catalyst and accordingly they may deactivate the catalyst either by covering of the active sites, and by pore blocking. Sometimes a distinction is made between coke and carbon [7]. The difference is however somewhat arbitrary: usually carbon is considered the product of $\mathrm{CO}$ disproportionation (2CO $\rightarrow \mathrm{C}+\mathrm{CO}_{2}$ ), whereas coke is referred to the material originated by decomposition (cracking) or condensation of hydrocarbons.

The chemical nature of the carbonaceous deposits depends very much on how they are formed, the conditions of temperature and pressure, the age of the catalyst, the chemical nature of the feed and products formed. Several authors pointed out a direct relationship between the amount of coke deposited and the aromatic and polynuclear aromatic content of the feed. Also, it has been reported that coke formation occurs more rapidly when a hydrogen acceptor, such as an olefin, is present, in line with the hypothesis of a carbonium ion chemistry for coke formation. In practice, the coke deposition may be controlled to a certain extent by using an optimal catalyst composition and an appropriate combination of process conditions [8].

During the reaction an equilibrium is reached between the rate of coke production and the rate of coke removal by gasifying agents (e.g. $\mathrm{H}_{2}, \mathrm{H}_{2} \mathrm{O}$ and $\mathrm{O}_{2}$ that remove coke as $\mathrm{CH}_{4}, \mathrm{CO}$ and $\mathrm{COx}$, respectively) so that steady-state conditions, corresponding to a certain level of coke present on the catalyst surface, are eventually reached. Otherwise, if the rate of coke deposition is higher than that of coke removal, a suitable regeneration procedure must be applied [9].

Catalysts used in naphtha reforming processes are bifunctional, as they contain a metal or dehydrogenation and hydrogenation functionality and acid-catalyzed isomerization functionality. The metal site is provided by platinum and metals promoters such as rhenium, tin, germanium, and iridium. The alumina support and chloride provide the acidcatalyzed isomerization functionality for the catalyst. The major goal of catalyst regeneration is to restore the catalyst to almost its fresh activity state where metal and acid sites are functioning as before coke deposition. To achieve this goal, the catalyst coke is burned off in a controlled manner, platinum and promoter metals are redispersed, and catalyst chloride is restored either to a fresh catalyst level or to a prescribed regenerated catalyst chloride level [10].

Catalyst deactivation, the loss over time of catalytic activity and/or selectivity is a problem of great and continuing concern in the practice of industrial catalytic processes. Costs to industry for catalyst replacement and process shut downs total billions of dollars per year[11] Catalyst regeneration is aimed at achieving the following objectives; a. High surface area, b) High dispersal of metal(Pt), c) Proper acidity level, d) decoking of the catalyst surface. Time scales for catalyst deactivation vary considerably for example in case of cracking catalysts, catalyst mortality may be I the order of seconds while in ammonia synthesis the iron catalyst may last 5- 10 years. However it is inevitable that all catalyst will decay [12]. Poor catalyst regeneration will lead to low product yields and increased operating expense, so good regenerations can improve catalyst performance, reduce operating costs, and lower catalyst management costs [13].

The unit studied in this work is SRR [14] which has three reactors, each with a fixed bed of catalyst, and all of the catalyst is regenerated in situ during routine catalyst regeneration shutdowns which occur approximately once each 6 to 24 months. Such a unit is referred to as a semiregenerative catalytic reformer (SRR). The unit is currently plagued with challenges of poor quality reformate yield and 
high costs of inputs due to high foreign exchange rates. This work is therefore directed at establishing appropriate conditions for catalyst regeneration, to achieve high/optimal activity of the catalyst that will enhance production of high quality reformates.

\section{Materials and Method}

\section{Experimental Procedures}

Regeneration

The procedures followed were adopted from literature [15]. The catalyst chosen for this experiment were industrial (KRPC - Kaduna Refining and Petrochemical Company in Kaduna state) fresh and two Spent $\mathrm{A} \& \mathrm{~B} \mathrm{Pt} / \mathrm{Al}_{2} \mathrm{O}_{3}$ naphtha reforming catalyst from CRU (Catalytic Reforming Unit). The Spent A \& B were collected online after 14000hours and 10000 hours cycle of reforming operation process.

Small (1.0g each) samples of the fresh and online collected spent A\&B (were crushed using laboratory mortar and pestle to powdered form and analysis (XRD, XRF, SEM, FTIR) were done on them and recorded. The experimental set up is shown in Figures $1-2$. The various portions of the two Spent A\&B catalysts to be used were initially weighed and recorded.. Each of the various parametric study operations were boosted with nitrogen to clear any form of hydrocarbon left on the spent catalyst and other impurities, making it inert. And the nitrogen flow kept constant at $2 \mathrm{~kg} / \mathrm{cm}^{2}$. The two spent catalyst sourced were calcined at different temperatures $\left(400^{\circ} \mathrm{C}, 500^{\circ} \mathrm{C}, 600^{\circ} \mathrm{C}, 700^{\circ} \mathrm{C}, 800^{\circ} \mathrm{C}\right)$, at constant air flow rate of $15 \mathrm{psi}$ for a reaction time of $4 \mathrm{hrs}$ each to obtain the optimum temperature. The spent catalyst was also calcined at optimum temperature and reaction time of $4 \mathrm{hrs}$ while the flow rate was varied @10psi, 15psi, 20psi, 25psi and 30psi. The spent catalyst was also calcined at optimum temperature and flow rate while the reaction time was varied @ 2hrs, $4 \mathrm{hrs}, 6 \mathrm{hrs}$ and $8 \mathrm{hrs}$

This is to study the effect of temperature; time and flow rate on the nature or pattern of regeneration i.e. amount of coke burnt off. This is shown in Figure $1-2$.

Catalysts' Reformation/Activity Performance Evaluations

In a typical run, about $2.0 \mathrm{~g}$ of the catalyst sample was packed (loaded) halfway within a tubular reaction vessel, a
$56 \mathrm{~cm}$ long by $1.0 \mathrm{~cm}$ internal diameter stainless 'silica tube'. The diagrammatic set-up is as shown in Figures 3. Glassfibres were placed before and after the catalyst bed to homogenize the reactant mixture and temperature. Prior to any reaction, the reactor's temperature was steadily increased to the desired reaction temperature $\left(465^{\circ} \mathrm{C}\right)$ and held at that temperature.

Treated Heavy Naphtha in a flask was heated (to vaporize) and the vapor was channeled downstream into the reactor. The vapor outlet (reformate) from the reaction zone was condensed as it passed through the condenser. The condensed reformate was collected as product. The procedure was done for fresh and the two spent catalyst at the same reaction temperature $465^{\circ} \mathrm{C}$ and feed flowrate. The constituents and compositions of reformate obtained in each case was determined with the aid of a QP2010 PLUS GC-MS machine. The reformate yield was later compared to check the activity of the catalyst. This is shown in Figure 3.

\section{Product Characterization}

The elemental composition (in oxide form) of product obtained was determined using the Energy Dispersive X-Ray Florescence (ED-XRF) machine (Minipal 4), and the X-ray diffraction (XRD) patterns were obtained using Empyreal, PANalytical diffractometer employing $\mathrm{Cu} K \alpha$ radiation $(\lambda=0.154 \mathrm{~nm})$, Scanning Electron Microscopy (SEM) imaging and Surface area using sear's method were conducted, Fourier Transform Infrared spectroscopy (FTIR) and Gas Chromatograph/Mass Spectrometry (GCMS) were obtained using SHIMADZU FTIR spectrometer and QP2010 PLUS GC-MS.

\section{Results and Discussion}

\subsection{FTIR Analysis of the Catalysts}

The operation conditions variation done on the two spent catalyst A \& B to obtain the optimum operating parameters for the regeneration process were all characterize using FTIR to affirm the best conditions observing the different functional groups present on the catalyst. Also the main objective is to ascertain the nature of coke species especially the soft coke.

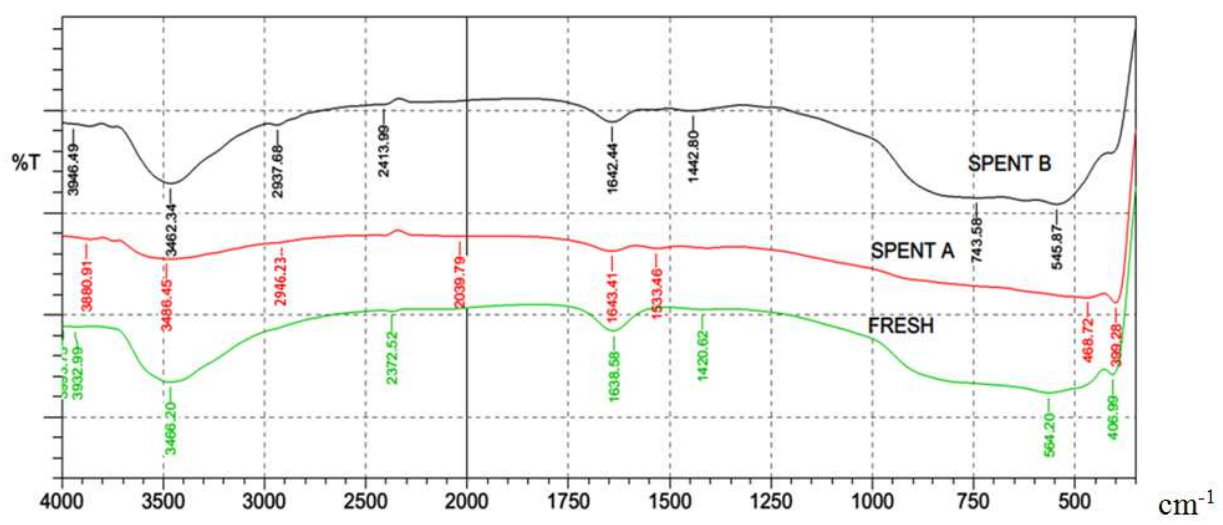

Figure 1. FTIR spectroscopy analysis of Fresh, Spent A \& Spent B catalyst before calcinations. 
The main absorption band in Figure 1 of Fresh catalyst at $3466.20 \mathrm{~cm}^{-1}$ corresponded to $\mathrm{NH}$ stretching vibrations of $\mathrm{NH}_{2}$ in aromatic amines and amides group. The absorption band at $1638.58 \mathrm{~cm}^{-1}$ corresponded to $\mathrm{C}=\mathrm{C}$ stretching of $\mathrm{C}=\mathrm{C}$ in alkenes. Likewise, the band observed at $564.20 \mathrm{~cm}^{-1}$ corresponded to chain deformation modes of alkyl group. This is in consonance with what was reported by Mario [16].

The absorption bands $3466.20,3486.45 \& 3462.34 \mathrm{~cm}^{-1}$ in the figure 4 of fresh, Spent A and Spent B respectively still affirmed $\mathrm{NH}$ stretching vibrations of $\mathrm{NH}_{2}$ in aromatic amines and amides group. The absorption band between 3000 and $2800 \mathrm{~cm}^{-1}$ are assigned to aromatic and aliphatic rings probably produced by polycyclic aromatics like chrysene. The absorption bands at $2946.23 \mathrm{~cm}^{-1} 2937.68 \mathrm{~cm}^{-1}$ (Spent A and Spent $\mathrm{B}$ )corresponded to $\mathrm{CH}$ antisym and sym stretching of $-\mathrm{CH}_{3}$ and $-\mathrm{CH}_{2}$ - in aliphatic compound which agree with symmetric and asymmetric flexion vibration of the $\mathrm{C}-\mathrm{H}$ bonds associated with $\mathrm{CH}_{3}$ [17]. All these can be linked to presence of commercial coke which is as a result of heavy unsaturated product from hydrocracking reaction during reforming such as poly-aromatics. Spent A with a band of
$2039.79 \mathrm{~cm}^{-1}$ confirms the presence of structure of aromatic compounds from the pattern of the weak overtone and combination tone bands. Also absorption band at $1643.41 \mathrm{~cm}^{-}$ ${ }^{1}$ (Spent A) and $1642.44 \mathrm{~cm}^{-1}$ (Spent B) also confirmed $\mathrm{C}=\mathrm{C}$ stretching of $\mathrm{C}=\mathrm{C}$ in alkenes i.e showing traces of heavy olefins and di-olefines that promote coking from the hydrocracking reaction effect on the catalyst. $1533.46 \mathrm{~cm}^{-1}$ absorption band on Spent A shows the presence of aromatic ring. Likewise the band $1442.80 \mathrm{~cm}^{-1}$ on Spent B corresponded $\mathrm{CH}_{3}$ antisym deformation of $\mathrm{CH}_{3}$ in aliphatic compounds as also seen on fresh catalyst.

The entire absorption band below $900 \mathrm{~cm}^{-1}$ confirms C-H out of plane bending, i.e. $743.5 \mathrm{~cm}^{-1}$ of spent B shows phenyl ring substitution bands as reported by Mario [16 ].

The deactivated (spent) catalysts were calcined at varying temperature, time and air pressure (oxygen level) using unifactorial method to know the range of operating conditions to be used for proper regeneration of the spent catalyst. The various results were characterized using FTIR and the spectra for each operating conditions can be seen cascaded in Figures 1-5.

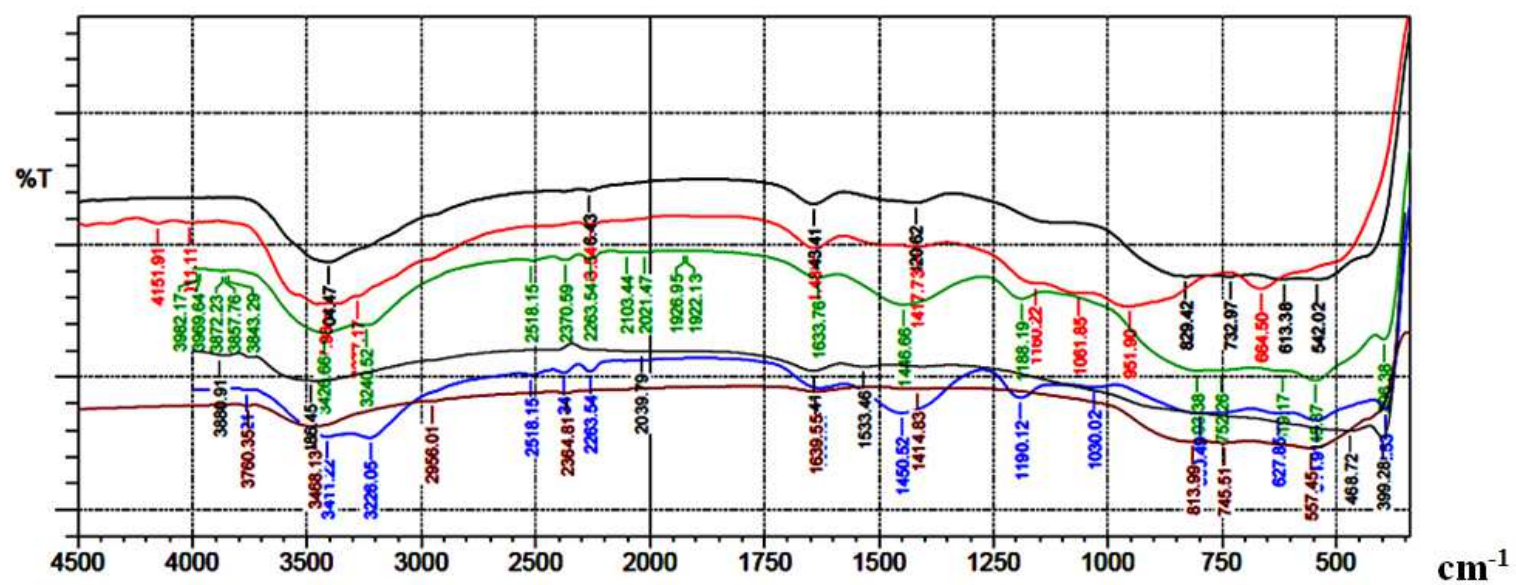

Figure 2. FTIR spectroscopy of Fresh \& Spent $A @ 400^{\circ} \mathrm{C}, 500^{\circ} \mathrm{C}, 600^{\circ} \mathrm{C}, 700^{\circ} \mathrm{C}$ and $800^{\circ} \mathrm{C}$ calcinations.

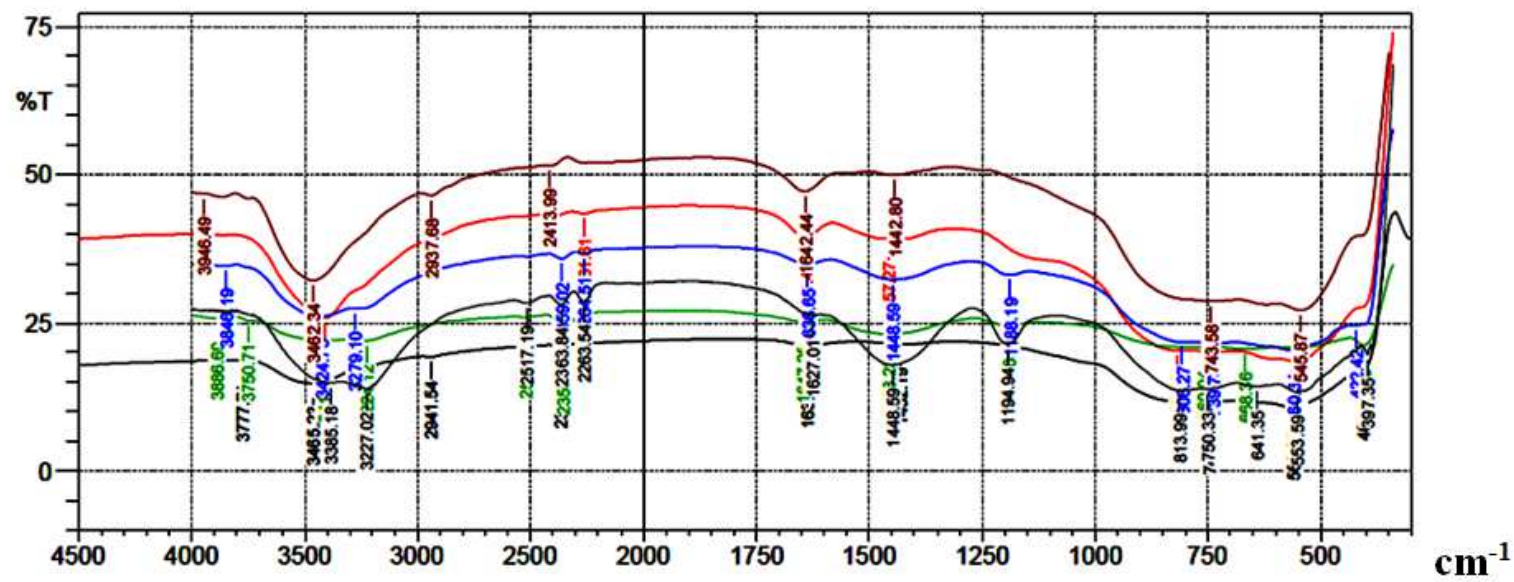

Figure 3. FTIR spectroscopy of Fresh \& Spent B@ $400^{\circ} \mathrm{C}, 500^{\circ} \mathrm{C}, 600^{\circ} \mathrm{C}, 700^{\circ} \mathrm{C}$ and $800^{\circ} \mathrm{C}$ calcinations. 


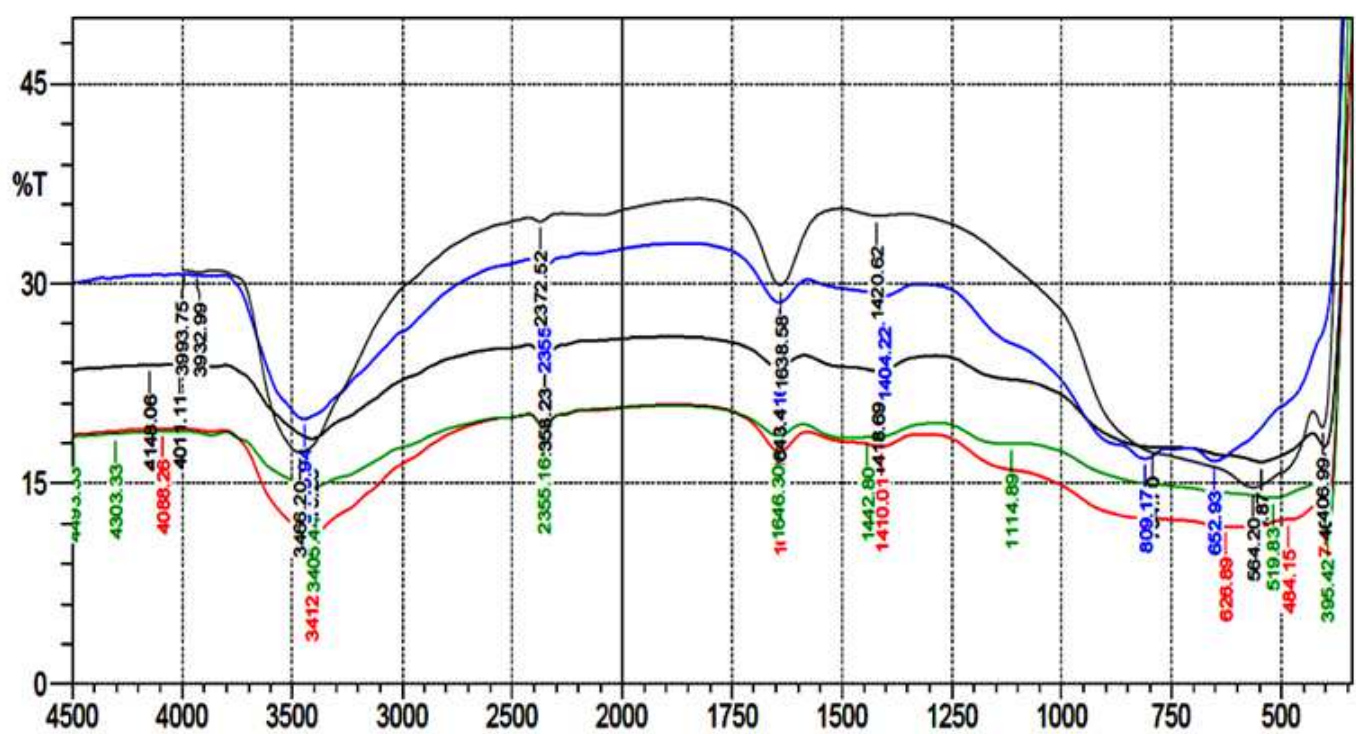

Figure 4. FTIR spectroscopy of Fresh, Spent A@500 $\mathrm{C}$ for 2, 4, 6 and 8 hours calcinations.

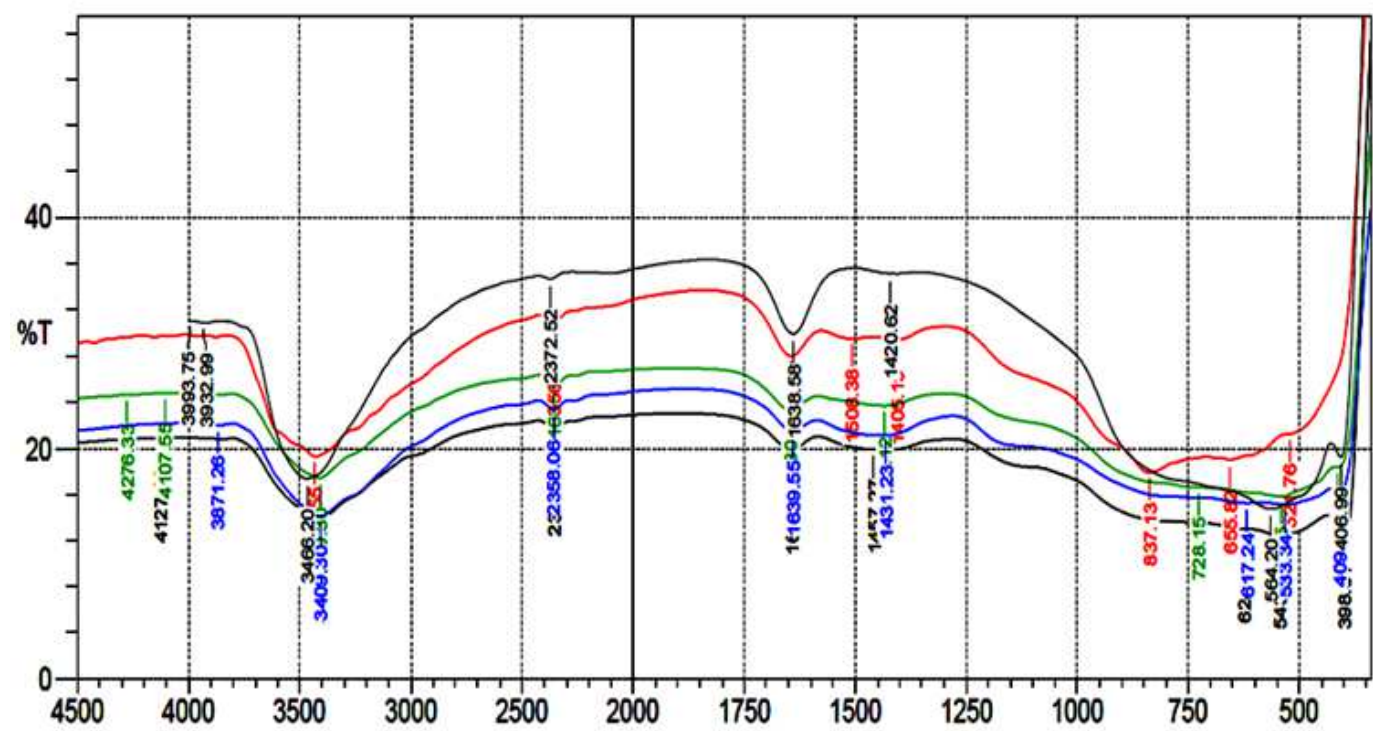

$\mathbf{c m}^{-1}$

Figure 5. FTIR spectroscopy of Fresh, Spent B @ 500 ${ }^{\circ} \mathrm{C}$ for 2, 4, 6 and 8 hours calcinations.

Comparing surface analysis technique showing the spectra of the fresh catalyst and deactivated spent catalysts subjected to different calcination temperatures. Figures $1-4$ present the spectra of calcined Spent $\mathrm{A}$ and $\mathrm{B}$ at $400^{\circ} \mathrm{C}, 500^{\circ} \mathrm{C}$ and $600^{\circ} \mathrm{C}$. it can be seen that the coke precursor from the deactivated spent catalyst that initially shows presence of coked catalyst $\left(2937.68 \mathrm{~cm}^{-1}\right.$ and $\left.2946.23 \mathrm{~cm}^{-1}\right)$ on Figures 2-4 but after the catalyst was calcined at different temperature $\left(400^{\circ} \mathrm{C}, 500^{\circ} \mathrm{C}\right.$ and $\left.600^{\circ} \mathrm{C}\right)$ under nitrogen gas. It shows that these coke precursors can be eliminated and there was reduction in adsorption of the olefin and the aromatic on the catalyst metal surface but much more lesser @ $400^{\circ} \mathrm{C}$ but at calcined temperature of $700^{\circ} \mathrm{C}$ and $800^{\circ} \mathrm{C}$ in Figure 2 shows same adsorption of olefin and aromatic and much more presence of coke on Figure $6\left(2956.01 \mathrm{~cm}^{-1}\right.$ on Spent A) and sintering were still observed.
From these observations, it can be concluded that a lower ramp rate is much more preferred for regeneration studies and it is in agreement with most industrial application as noted by previous workers [18] that showed that low temperatures are usually employed to enhance better control of the coke combustion.

Temperature effect on the spent catalyst under nitrogen gas in Figure 2 of $400^{\circ} \mathrm{C}, 500^{\circ} \mathrm{C}, 600^{\circ} \mathrm{C}$ also produces absorption bands range $2100-2270 \mathrm{~cm}^{-1}$ showing small but exposed presence of $\mathrm{CC}$ triple bond distribution (corresponding to $\mathrm{CC}$ triple bond stretching) presence of combustion which is as a result of hydrocracking not needed in reforming process leading to coke formation.

Considering time variation with optimum temperature $\left(500^{\circ} \mathrm{C}\right)$ and a lower air pressure $(15 \mathrm{psi})$ chosen as a result of conditions with highest percentage weight loss of deposit on 
the two deactivated spent catalyst. Figure 4-6 showing cascaded time variation for spent A \& B respectively shows little or no variation change in peaks i.e. showing all functional group that can be seen in the fresh catalyst but in terms of percentage weight loss for 2, 6 and $8 \mathrm{hrs}$ are lower compare to that of 4hours. Meaning that coke combustion occurs more within 4hours and reduces with any further increase in time.

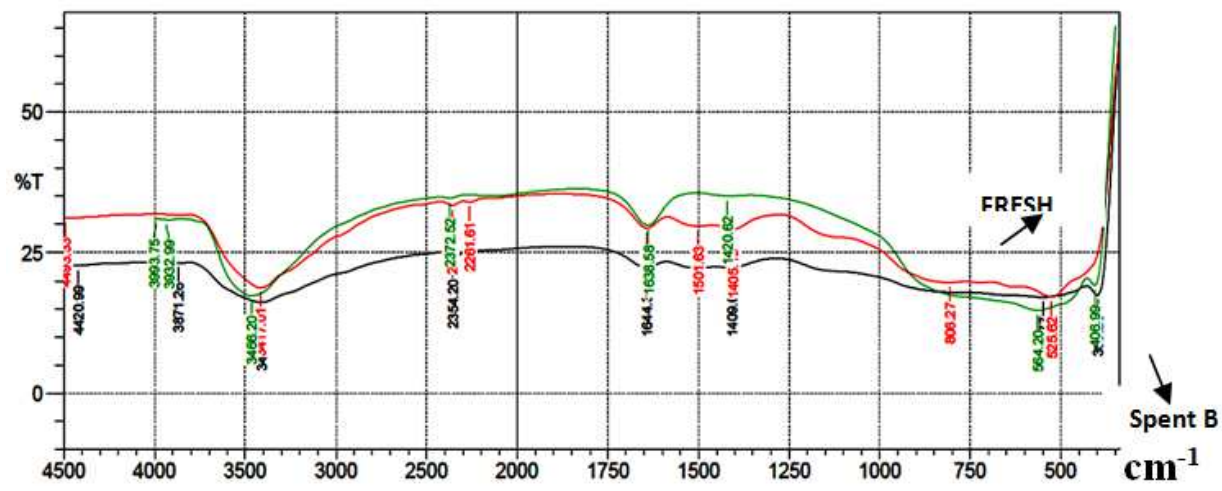

Figure 6. FTIR spectroscopy analysis of Fresh, Regenerated Spent A \& Regenerated Spent B catalyst. The main absorption bands in Figure 6 at $3417.01 \mathrm{~cm}^{-1}$ (spent A) and $3410.26 \mathrm{~cm}^{-1}$ (spent B) corresponded $\mathrm{OH}$ stretching vibrations (due to OH-Pt bond) i.e. hydrogen bonded in alcohols and phenols. The absorption bands at 2359.02, 2354.20 and $2261.61 \mathrm{~cm}^{-1}$ has no significant effective functional group because they have weak intensity while absorption band at 1644.37 and $1641.48 \mathrm{~cm}^{-1}$ corresponded $C=C$ stretching of $C=C$ in alkenes and are possible due to the adsorption of olefin and aromatics on the catalyst metal surface [19]. This may indicate that the coke species found near the active metal are soft coke and it is mainly made up of unsaturated hydrocarbon and heavy aromatics. Likewise, the bands observed at $806.27,545.77,525.62$ and $399.28 \mathrm{~cm}^{-1}$ corresponded to chain deformation modes of alkyl group. This is in consonance with what was reported by other workers $[20,16]$. The results also confirmed that, the industrial or commercial coke catalyst 3000 and $2800 \mathrm{~cm}^{-1}$ are missing. This shows that eliminated of these coke precursors after treatment under nitrogen gas in the presence of controlled air is possible but it can't show how active the regenerated spent catalysts except a catalyst performance test is done.

For further comparison, some other cascading was done and shown in figure 6 and 7 comparing each spent catalyst with the fresh and its regenerated catalyst.

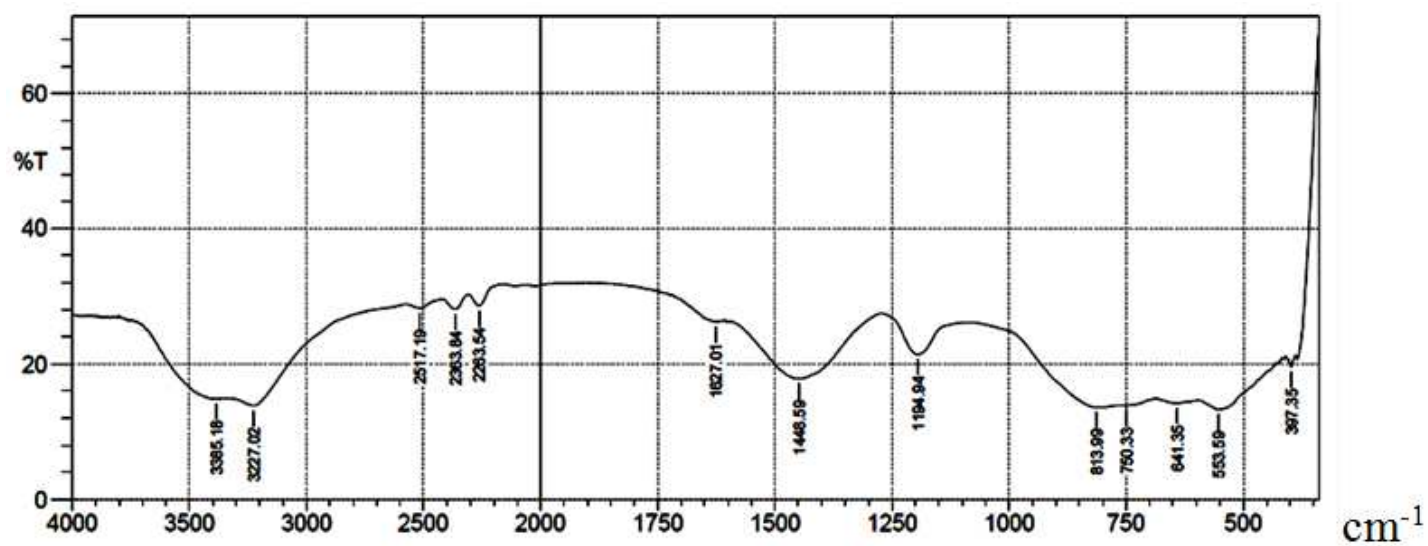

Figure 7. FTIR spectroscopy analysis of Spent B on $400^{\circ} \mathrm{C}$ calcinations.

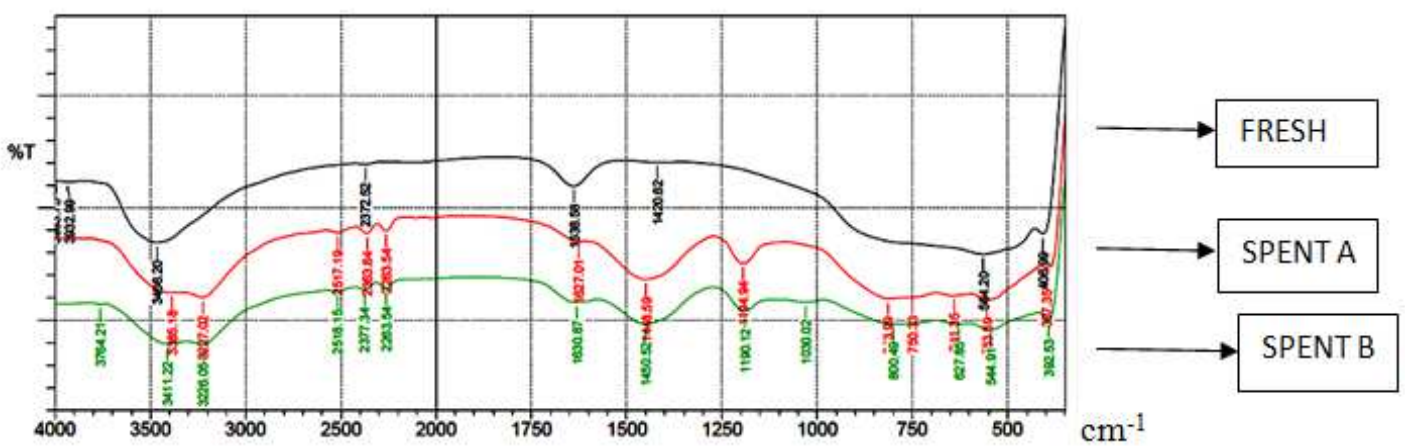

Figure 8. FTIR spectroscopy of Fresh, Spent A\& Spent B catalyst@400C calcinations. 


\subsection{Carbon Composition of Catalyst}

The organic carbon content composition was carried using the Walkley black method. The percentage carbon on each catalyst was tabulated in Table 1.

Table 1. Carbon Composition on Catalyst.

\begin{tabular}{ll}
\hline Catalyst & Carbon Composition (\%) \\
\hline Fresh & 0.012 \\
Spent A & 0.317 \\
Spent B & 3.705 \\
Regenerated Spent A & 0.189 \\
Regenerated Spent B & 0.317 \\
\hline
\end{tabular}

The composition in table 1 shows considerable deposition of carbon on the catalyst during reforming at the specific collected life cycle of the spent catalyst A \& B. it was observed that there was much deposit of carbon on the first collected catalyst (Spent B) possibly due to the presence of more hydrocracking reaction that took place. The high carbon deposits found on the deactivated catalyst were decrease after regeneration due to the burning off the coke (carbon) deposited on the catalyst. The presence of carbon on the fresh catalyst could be as a result of sample of having been exposed to atmosphere and being a catalyst it can adsorb.

\subsection{Morphology of Catalysts}

The SEM image of the fresh catalyst and XRD patterns of the fresh and spent catalysts are shown in Figures 9-10.
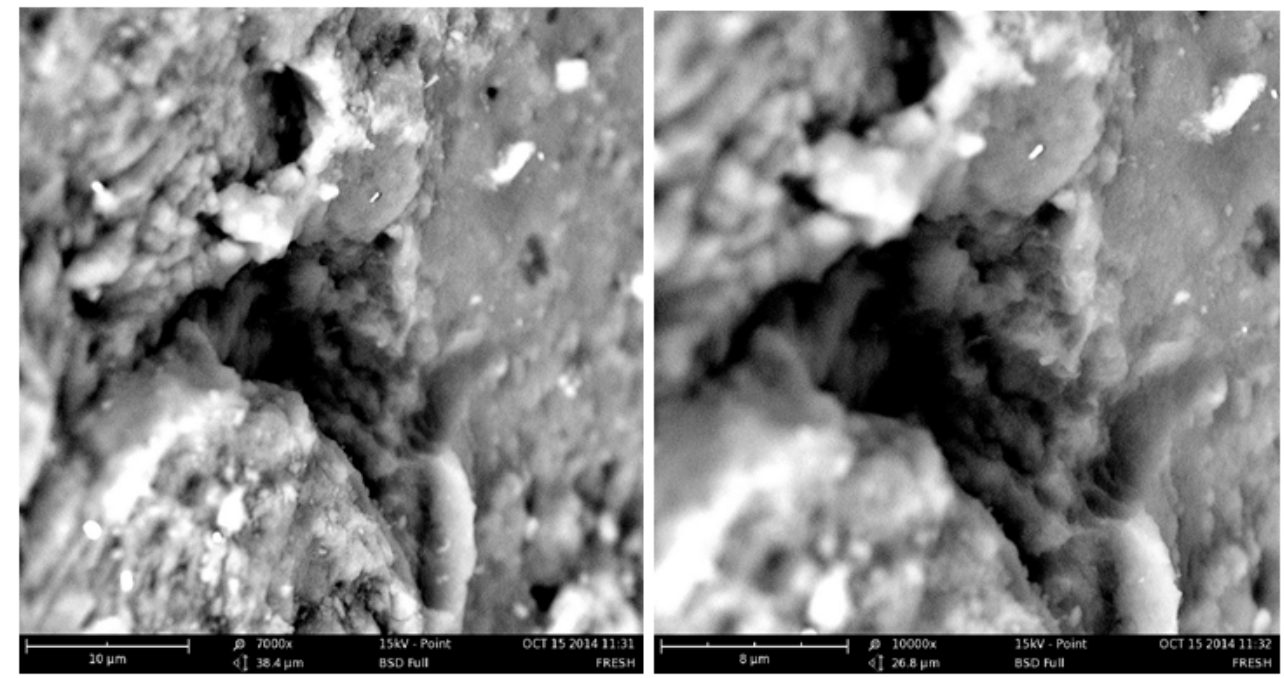

Figure 9. SEM images of Fresh catalyst.

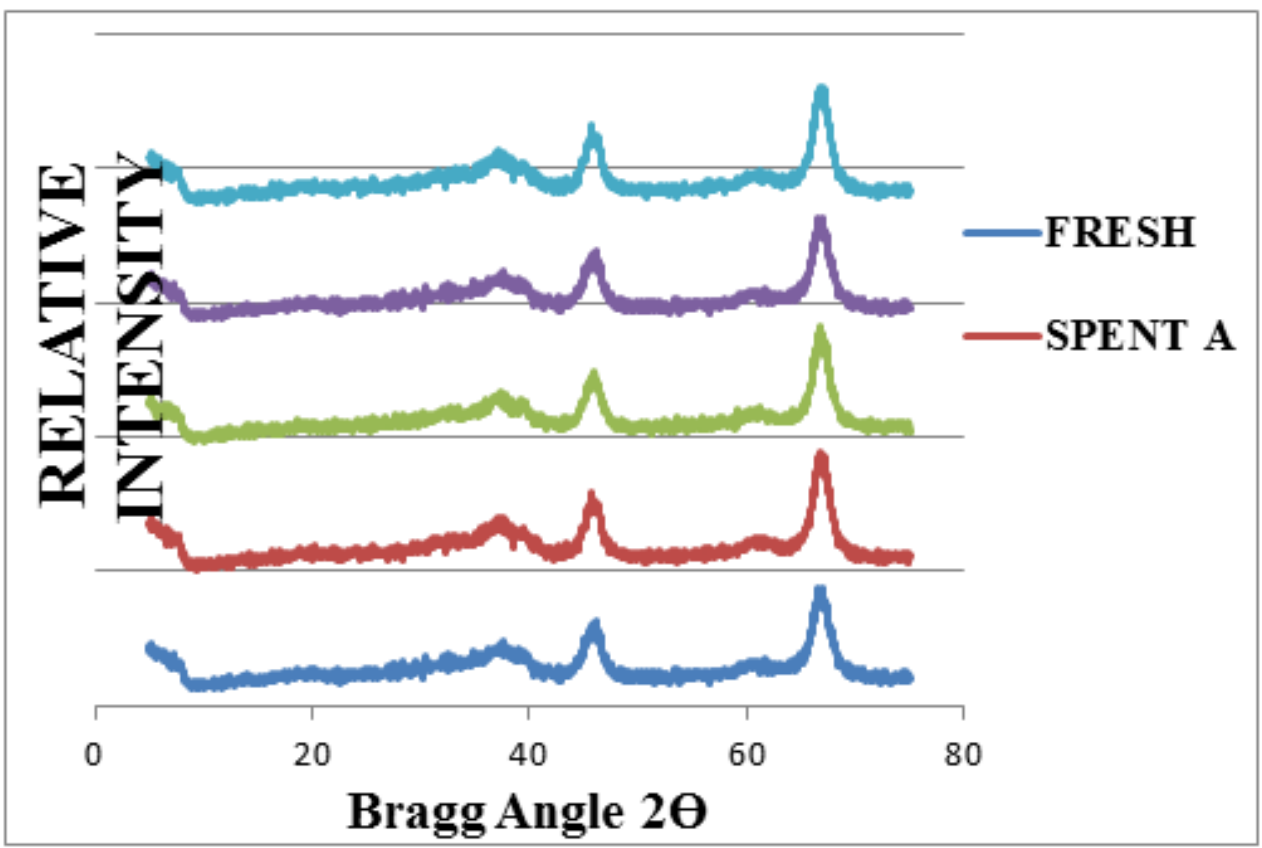

Figure 10. XRD patterns of the fresh, two spent catalysts and the regenerated catalysts. 
The XRD diffractograms obtained from Empyreal PANalytical Diffractometer for the catalysts (fresh, Spent A \& B) are as shown in Figure 9 above.

The low intensity counts and the broad peaks that characterized the diffractographs of the support $\left(\gamma-\mathrm{Al}_{2} \mathrm{O}_{3}\right)$ averred to the fact that the gamma-alumina is amorphous.

The platinum catalysts have closely related bragg angles ( $2 \theta \mathrm{s})$ with those of the support (alumina), but little or no significant difference with their intensity counts.

The XRD diffraction peaks and bragg angles for platinum exist at $40^{\circ}, 47^{\circ}, 68^{\circ}$ (Figure 10) for all the catalyst which appears to coincide with the support (gamma-alumina) which exist at $37^{\circ}, 39^{\circ}, 46^{\circ}, 60^{\circ}, 67^{\circ}$ except that platinum shows a distinct peak at $47^{\circ}$ and $68^{\circ}$. These interpretations agree with the works of $[19,20]$. The works of Yasuharu [21] also corroborated the fact of XRD pattern of platinum has bragg angles of $17^{\circ}, 40^{\circ}, 46^{\circ}, 67^{\circ}$. Likewise, Gobara [22] affirmed that $\mathrm{Pt} / \mathrm{Al}_{2} \mathrm{O}_{3}$ catalyst have Bragg angles of $39.8^{\circ}, 46.5^{\circ}$ and $67.8^{\circ}$ which are attributes of $\mathrm{Pt}$ metallic phase in cordance with the ICDD database: JCPDS 01-1190.

Platinum and the Alumina are dominant as also reflected from XRF. Despite the heat effect on regeneration of the catalysts it shows that thermally the structure is not destroyed and carbon has no much significance on the structure of the catalysts.

\subsection{XRF Analysis}

The XRF of the fresh, spent and regenerated catalysts are shown in Table 2.

Table 2. XRF of the catalystsResult of analysis (OXIDE \%).

\begin{tabular}{|c|c|c|c|c|c|}
\hline & FRESH & SPENT A & SPENT B & REGENERATED SPENT A & REGENERATED SPENT B \\
\hline $\mathrm{SiO}_{2}$ & 1.03 & & 0.59 & 0.32 & 0.78 \\
\hline $\mathrm{Al}_{2} \mathrm{O}_{3}$ & 89.9 & 92.23 & 92.2 & 91.89 & 91.08 \\
\hline $\mathrm{K}_{2} \mathrm{O}$ & 0.01 & _- & 0.03 & - & _- \\
\hline $\mathrm{Na}_{2} \mathrm{O}$ & $<0.01$ & $<0.01$ & $<0.01$ & $<0.01$ & $<0.01$ \\
\hline $\mathrm{MgO}$ & 0.02 & - & 0.04 & - & 0.04 \\
\hline $\mathrm{P}_{2} \mathrm{O}_{5}$ & 0.78 & $\overline{0} .64$ & 0.48 & $\overline{0} .68$ & 0.59 \\
\hline $\mathrm{Cl}$ & 2.95 & - & - & 0.98 & 1.08 \\
\hline $\mathrm{CaO}$ & 0.278 & $\overline{0} .322$ & $\overline{0} .269$ & 0.301 & 0.265 \\
\hline $\mathrm{TiO}_{2}$ & 0.20 & 0.410 & 0.408 & 0.382 & 0.26 \\
\hline $\mathrm{V}_{2} \mathrm{O}_{5}$ & 0.18 & 0.275 & 0.15 & 0.242 & 0.17 \\
\hline $\mathrm{Cr}_{2} \mathrm{O}_{3}$ & 0.14 & _- & 0.13 & 0.09 & 0.13 \\
\hline $\mathrm{MnO}$ & 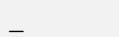 & 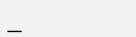 & 0.025 & - & 0.014 \\
\hline $\mathrm{Fe}_{2} \mathrm{O}_{3}$ & 0.032 & 1.02 & 2.51 & 0.84 & 1.02 \\
\hline $\mathrm{NiO}$ & 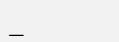 & 0.022 & 0.013 & 0.014 & 0.010 \\
\hline $\mathrm{CuO}$ & 0.042 & 0.030 & 0.034 & 0.032 & 0.034 \\
\hline $\mathrm{ZnO}$ & 0.02 & 0.082 & 0.051 & 0.04 & 0.031 \\
\hline $\mathrm{ZrO}_{2}$ & 0.4 & _ & 0.4 & 0.12 & 0.4 \\
\hline $\mathrm{Ag}_{2} \mathrm{O}$ & 0.03 & 0.89 & 0.01 & 0.67 & 0.43 \\
\hline $\mathrm{BaO}$ & 0.74 & 0.56 & 0.33 & 0.64 & 0.42 \\
\hline $\mathrm{ReO}_{7}$ & 0.1 & - & & & \\
\hline $\mathrm{PtO}_{2}$ & 2.47 & 2.38 & 2.13 & 2.39 & 2.26 \\
\hline $\mathrm{IrO}_{2}$ & & 0.42 & & & \\
\hline TOTAL & 99.332 & 99.291 & 99.81 & 96.641 & 99.024 \\
\hline
\end{tabular}

Table 2 shows the percentage oxide form of elemental composition using XRF. The alumina $\left(\mathrm{Al}_{2} \mathrm{O}_{3}\right)$ and the platinum were more dominant and it could be seen that there was a proportional increase in the support (alumina) after reforming has taken place on the deactivated catalyst compared to fresh catalyst ( $89.9 \%$ to $92.23 \%$ Spent A $89.9 \%$ to $92.2 \%$ Spent B). While little decrease in platinum $(2.47 \%$ to $2.38 \%$ Spent A and $2.47 \%$ to 2.13 Spent B) and loss of chlorine which was completely used up during reforming process.

Majorly the fluctuation of the oxide was as a result of the loss of chlorine which was completely used up spreading across some of the other oxides for example alumina material increased probably as a result of chlorine loss and decrease of masses of other oxides. And due to the effect of calcinations (regeneration) burning or removal of some carbonaceous material, chlorine which was earlier used up resurfaced on the catalyst after the activity was boosted with dichloropropane and the alumina (support) decreases while other oxides too regained almost their original compositions. The pore fibre length of and pore distribution the fresh, spent and regenerated catalysts are shown in Figures $10-17$.

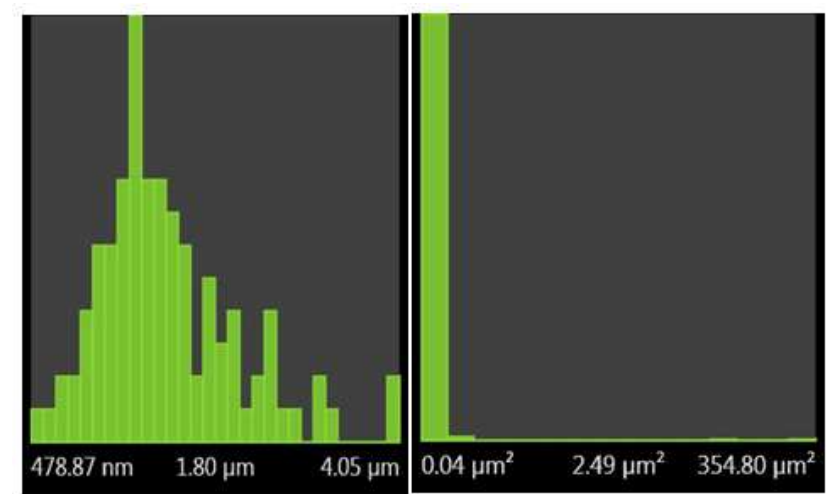

Figure 11. a Fresh catalyst Pore-fibre length Histogram (b) Fresh catalyst Pore-Surface area histogram. 

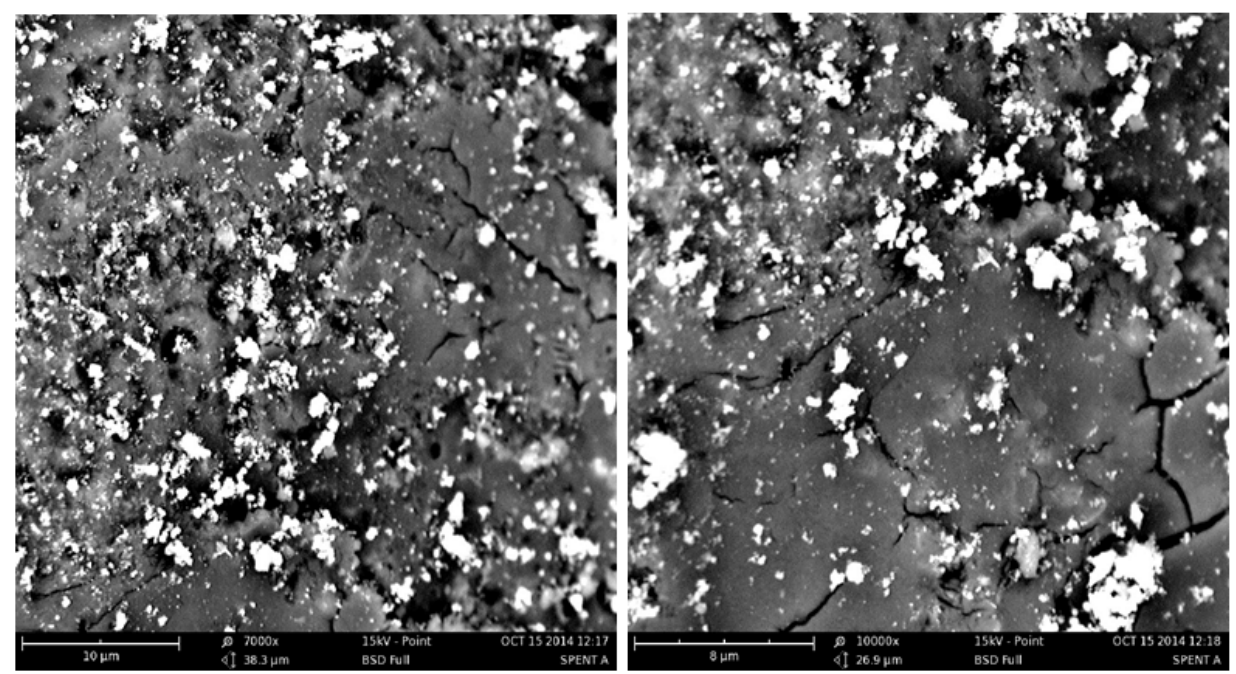

Figure 12. SEM images of Spent A catalyst.
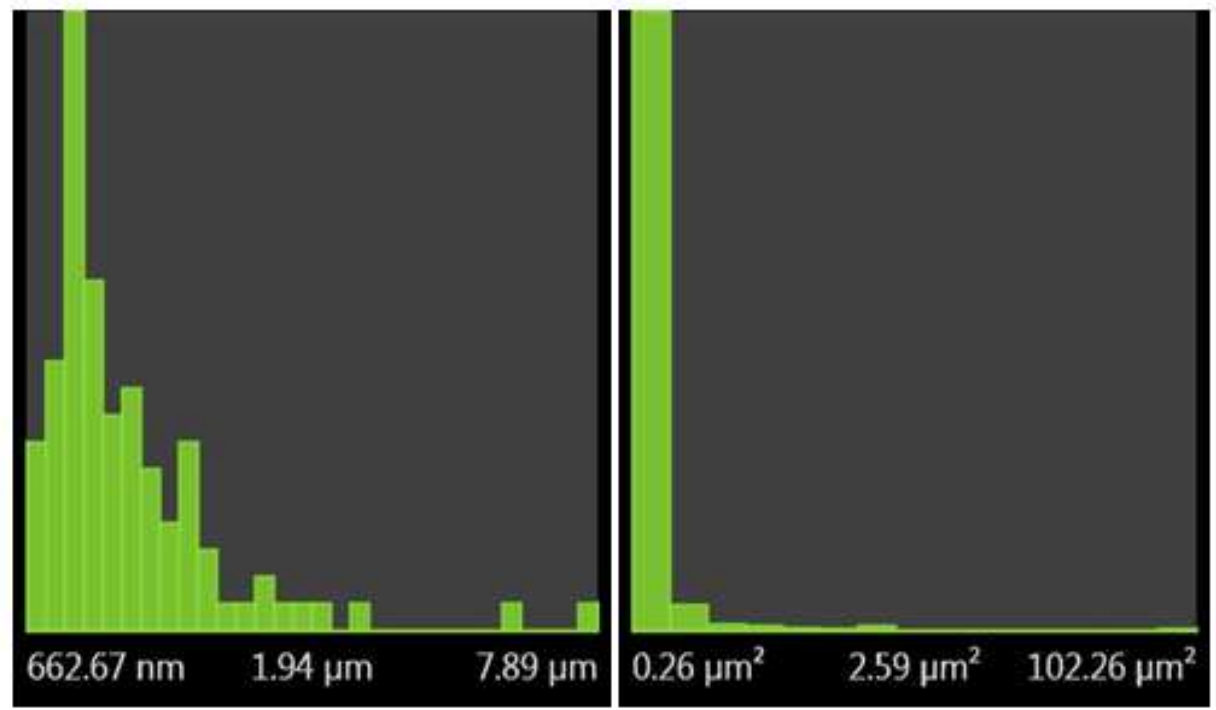

Figure 13. (a) Spent A Pore-fibre length Histogram (b) Spent A Pore-Surface area histogram.
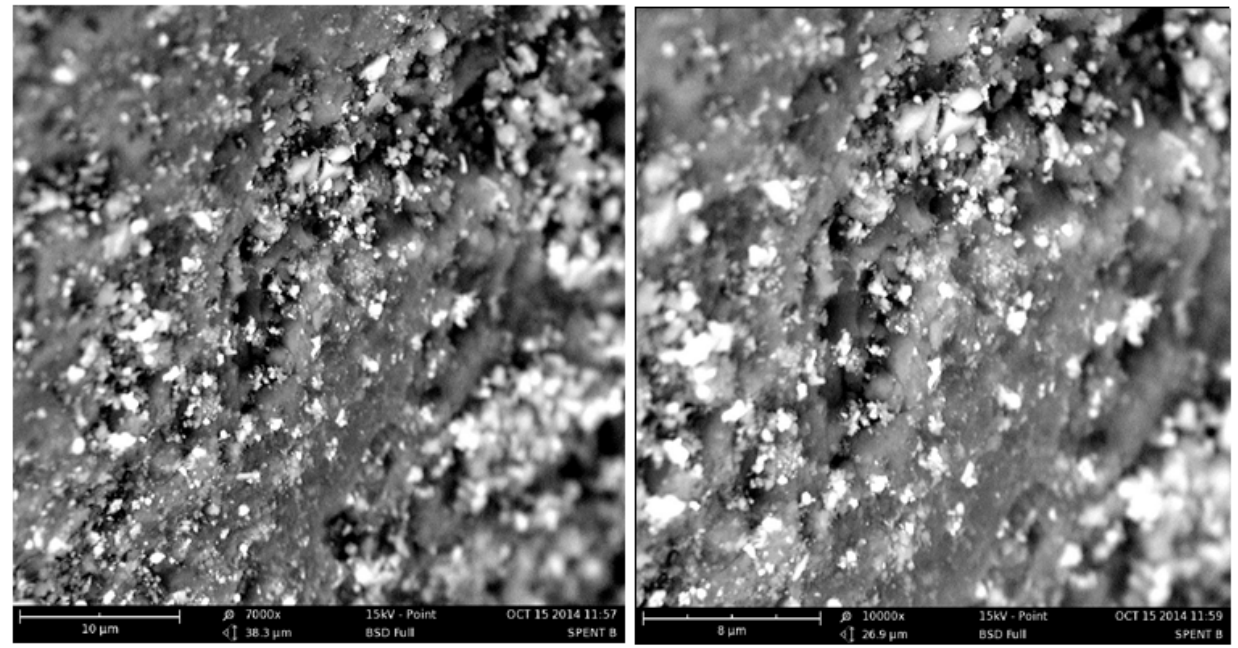

Figure 14. SEM images of Spent B catalyst. 

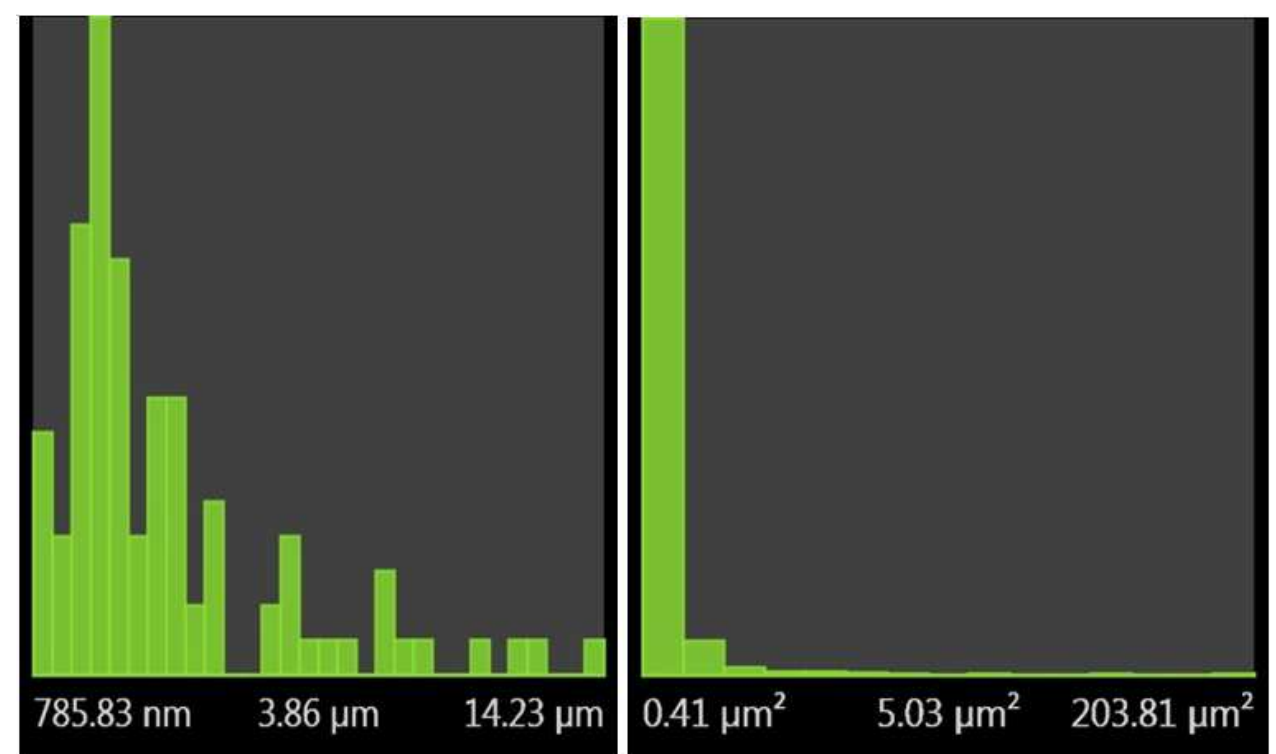

Figure 15. (a) Spent B Pore-fibre length Histogram (b) Spent B Pore-Surface area histogram.
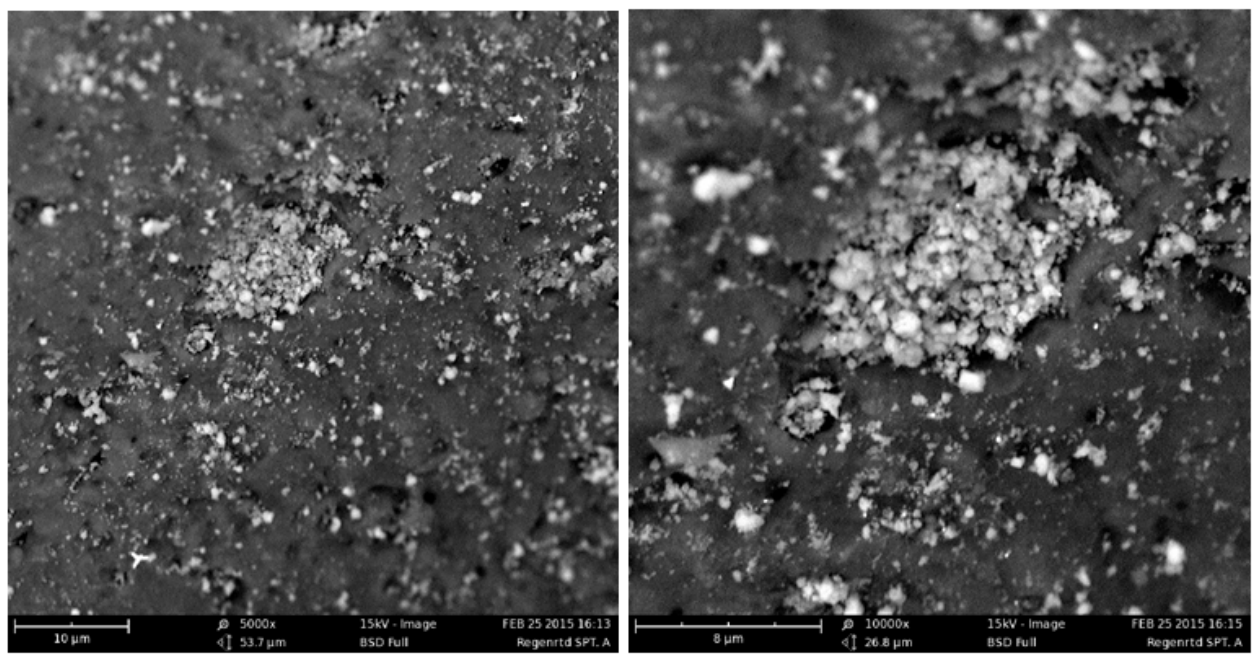

Figure 16. SEM images of Regenerated Spent A catalyst.
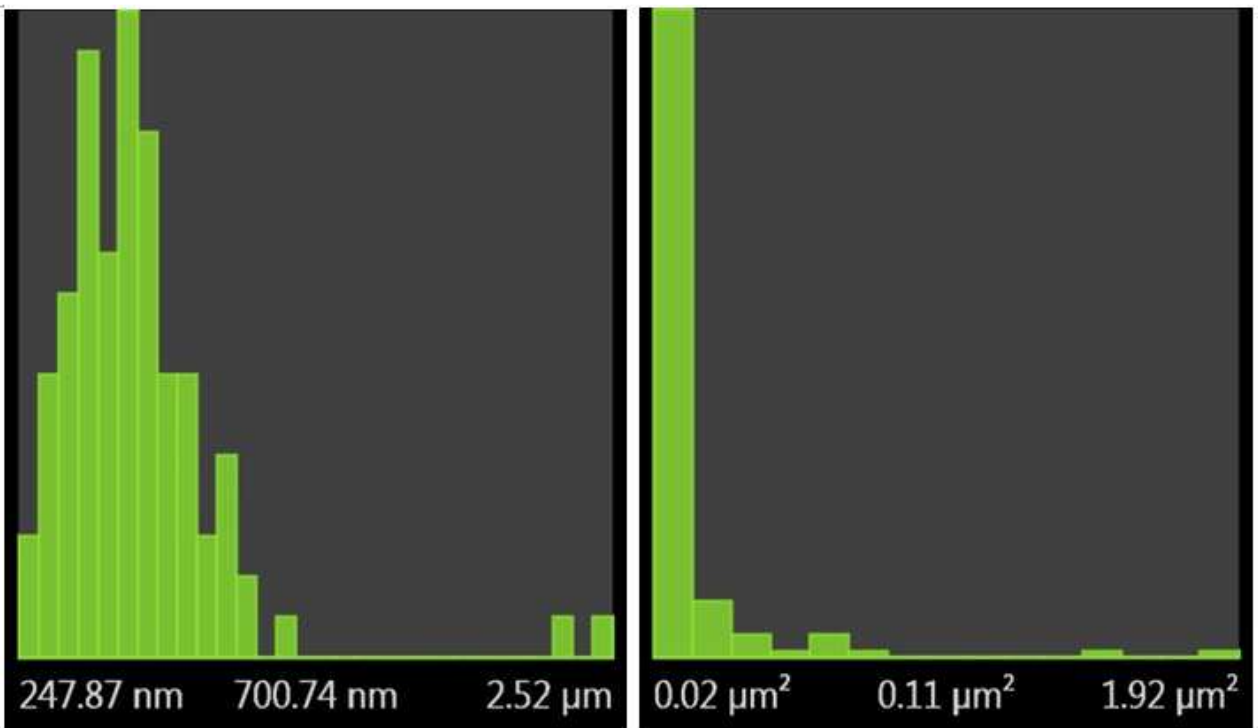

Figure 17. (a) Regenerated Spent A Pore-fibre length Histogram (b) Regenerated Spent A Pore-Surface area histogram. 

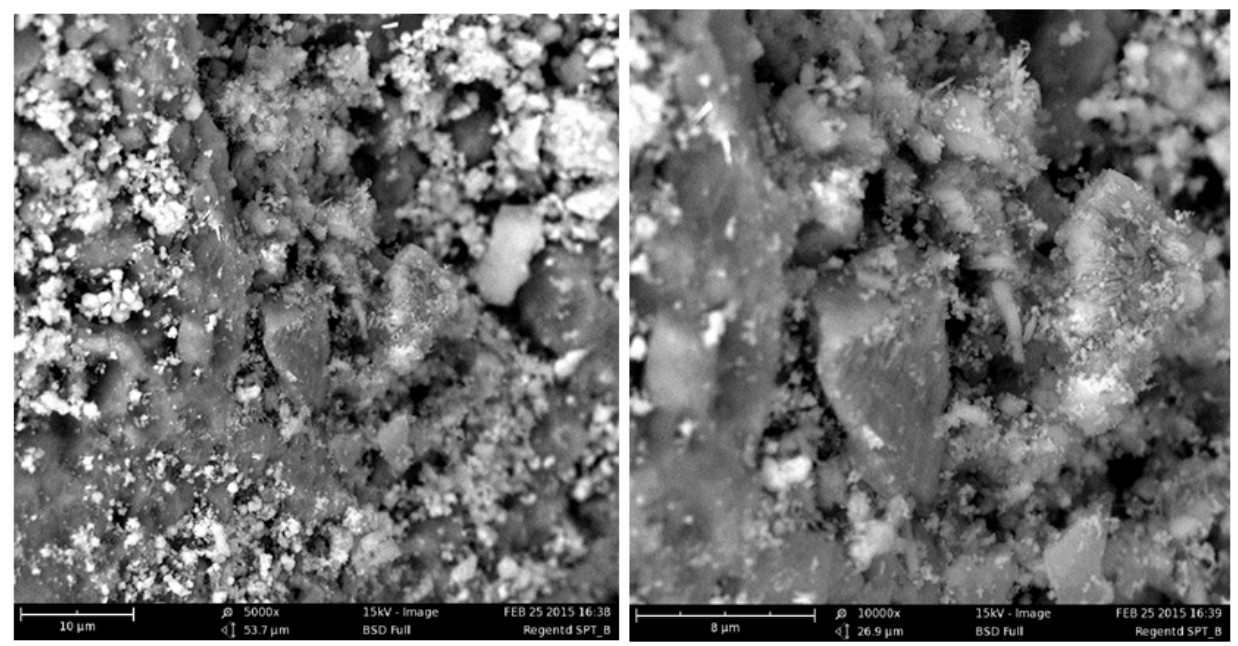

Figure 18. SEM images of Regenerated Spent B catalyst.
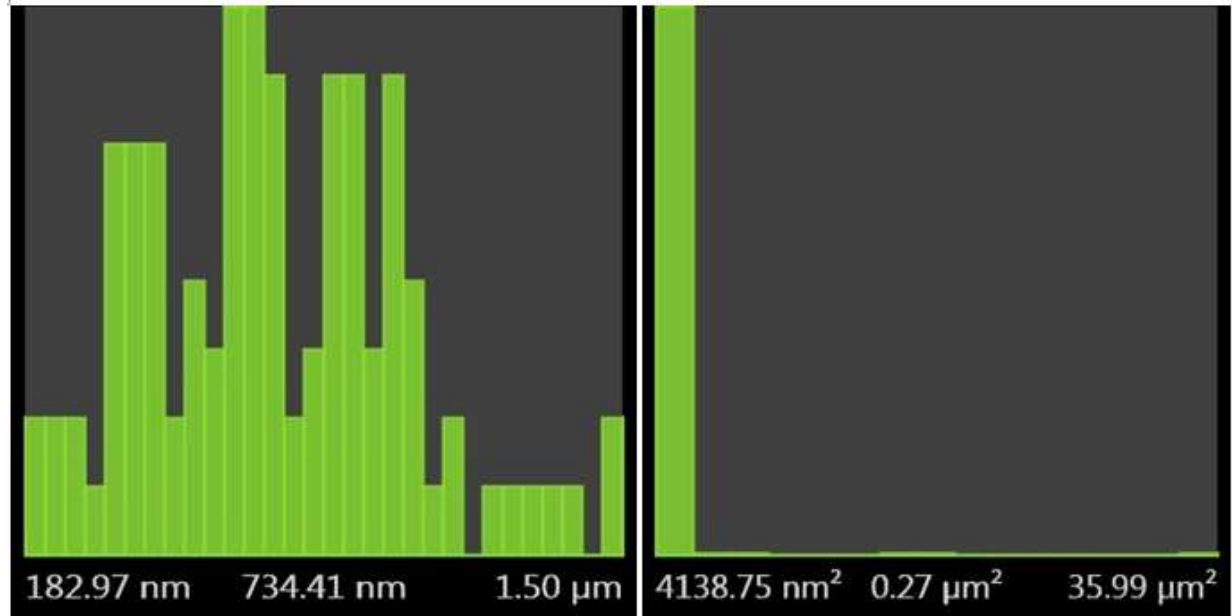

Figure 19. (a) Regenerated Spent B Pore-fibre length Histogram (b) Regenerated Spent B Pore-Surface area histogram.

Figures 11 - 18 show the SEM images obtained for each of the catalysts sample. Figure 10 which show the image of fresh catalyst, one could observe uniformity in the crystal size (cluster) of platinum metal and geometric distribution of the amorphous nature of the support (alumina) for $8 \mu \mathrm{m}$ and $10 \mu \mathrm{m}$ magnification. But Figures $15 \mathrm{a}$ and $15 \mathrm{~b}$ of deactivated catalyst Spent A \& B shows the presence of heavy mass of organic compound deposit on temperature effect which made the support more disperse all over given rise to little deposit of black spots of carbon amidst the catalyst and blockage of some pores. But after regeneration (Figure 13a and 13b), the carbon deposit are reduced, more opened pores are observed and we could observe clusters appearing back majorly in Figure 19a with less carbon deposit.

Also from Figures10a-10c of the fresh, spent A \& B and regenerated spent $A \& B$ respectively. It can be seen that the SEM image surface area is divided into micro, meso and macro pore group. The surface area became more opened on regeneration of the catalyst for both spent A\&B after chemical and thermal treatment burnt off some of the carbonaceous material deposited on the catalyst. This was clearly shown in the increment in the small, average and large surface area as shown in the summary given in Table 3.

Table 3. Surface Area Transition of Catalyst.

\begin{tabular}{llll}
\hline \multirow{2}{*}{ Catalyst } & \multicolumn{2}{c}{ Surface Area } & \\
\cline { 2 - 4 } & Small(Micro) & $\begin{array}{l}\text { Average } \\
\text { (Meso) }\end{array}$ & $\begin{array}{l}\text { Large } \\
\text { (Macro) }\end{array}$ \\
\hline Fresh & $0.04 \mu \mathrm{m}^{2}$ & $2.49 \mu \mathrm{m}^{2}$ & $354.80 \mu \mathrm{m}^{2}$ \\
Spent A & $0.02 \mu \mathrm{m}^{2}$ & $0.11 \mu \mathrm{m}^{2}$ & $1.92 \mu \mathrm{m}$ \\
Spent B & $4138.75 \mathrm{~nm}^{2}$ & $0.27 \mu \mathrm{m}^{2}$ & $35.99 \mu \mathrm{m}^{2}$ \\
Regenerated A & $0.26 \mu \mathrm{m}^{2}$ & $2.59 \mu \mathrm{m}^{2}$ & $102.26 \mu \mathrm{m}^{2}$ \\
Regenerated B & $0.41 \mu \mathrm{m}^{2}$ & $5.03 \mu \mathrm{m}^{2}$ & $203.81 \mu \mathrm{m}$ \\
\hline
\end{tabular}

The catalysts textural properties are also shown in Table 4.

Table 4. Specific Surface Area of the catalysts.

\begin{tabular}{lll}
\hline Catalyst & & Specific Surface Area $(\mathrm{SSA})\left(\mathbf{m}^{2} / \mathbf{g}\right)$ \\
\hline FRESH & & 365.4 \\
\multirow{2}{*}{ SPENT } & A & 147.8 \\
& B & 183.0 \\
REGENERATED & A & 208.6 \\
& B & 215.0 \\
\hline
\end{tabular}

The specific surface area was determined using Sear's method and presented in Table 4. There were significant increases in the regenerated catalyst compare to the 
deactivated catalyst (spent A \& B). SSA (Specific surface area) for of spent A increased by $41 \%$ while spent B increased by $17 \%$. The large percentage increase was as a result of the method used to obtain the surface area, but increase in surface area results to slight improvement in the surface morphology.

All deactivated catalysts have smaller specific surface area than the fresh catalyst. Comparatively the spent A deactivated catalyst has the least specific surface area, this is because organic compounds with higher boiling points have covered the catalyst surface more than that of spent B which results in the decrease of the specific surface area compared to fresh catalyst.

\subsection{Catalysts' Performance Evaluations}

The catalyst performance evaluation was examined on the basis of catalyst's ability to enhance the yield of reformate from treated heavy naphtha. The treated heavy naphtha feed was not pure The assumed composition of the byproducts (i.e the dry gases) in the entire products was cited from the work of Karla [23]. The operating reaction temperature used for the reforming was $465^{\circ} \mathrm{C}$ for the various catalysts packed.

$$
\text { Treated heavy naphtha } \stackrel{\text { reforming }}{\longrightarrow} \text { Products }
$$

$$
\begin{gathered}
\text { Product }=\text { Sample collected }+ \text { byproducts } \\
\text { Byproducts }=\left(\mathrm{H}_{2}+\text { Off-gases }+ \text { LPGs }\right)=X
\end{gathered}
$$

Sample collected $=$ Unconverted feed $(N)+$ reformate $(R)$

Hence, from the chromatograms of each sample analyzed, the area assigned to the unconverted treated heavy naphtha was taken as $\mathrm{N}$, while the total area assigned to all reformates was taken as $\mathrm{R}$.

\subsection{Component Identification Method}

\section{Quantitative analysis}

The quantitative analysis of the reformate obtained from the regenerated and fresh catalysts was carried using the GCMS.. The GC-MS system used, have computer software used to draw and integrate peaks, and thus match the obtained MS spectra to library spectra. Thus, an analytes present in a sample eluting from the column was named by matchmaking, and the most likely analyte's names were given (in order of probability; SI) in each spectrum. For instance, the spectrum (connoted by the GC-MS machine as Hit\# 1) shown in Figure 20 is "Benzene"- which is the compound name with its isomers (each placed within the two doubledollar-sign).

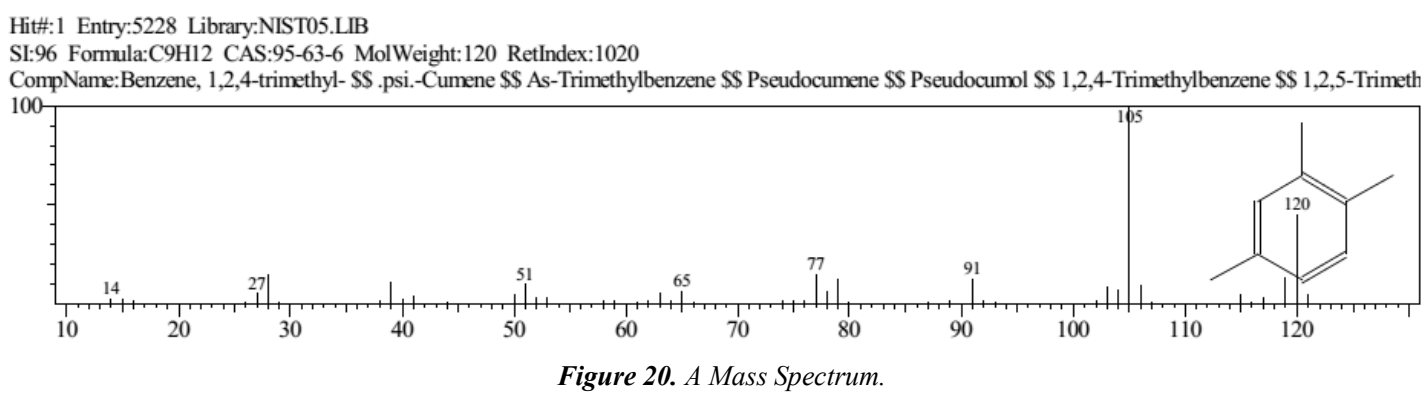

The performance evaluation results are presented in Table 5.

Table 5. Summary of Catalysts Performance Evaluations.

\begin{tabular}{lllll}
\hline Catalyst & Isoparaffin (\%) & Aromatic (\%) & Max Yield attained (\%) & \% Activity with fresh catalyst as basis \\
\hline Fresh & 71.67 & 5.81 & 84.24 & 100.00 \\
Spent A & 57.48 & 2.98 & 80.66 & 95.75 \\
Spent B & 59.52 & 6.11 & 81.90 & 97.22 \\
Regenerated Spent A & 59.64 & 12.14 & 83.19 & 98.75 \\
Regenerated Spent B & 67.64 & 7.70 & 83.86 & 99.55 \\
\hline
\end{tabular}

From Table 5 it can be seen that the fresh catalyst has the highest yield of reformate $(84.24 \%)$ produce and that of the deactivated catalyst dropped a little due to the presence of carbonaceous material deposited on them, after regeneration the percentage reformate yield increased but still very close to the fresh in terms of percentage. In terms of activity of the catalyst, the before and after the extent the catalyst went through during regeneration the activity is still high for the deactivated and regenerated catalyst showing that the performance is very close to fresh catalyst which was taken as basis. Taking Spent A for example has 95.75\% activity compare to fresh $(100 \%)$ and also after regeneration the activity increase a little but still within the limit.

\section{Conclusion}

The catalyst life span and catalyst efficiency is critical to the operation of catalytic reforming units. This work has established a technological range of conditions for regeneration of $\mathrm{Pt} / \mathrm{Al}_{2} \mathrm{O}_{3}$. catalyst employed in a fixed bed semi regenerative catalytic reforming unit. This work established that all deactivated catalysts have smaller specific surface area than the fresh catalyst. Comparatively the spent A deactivated catalyst has the least specific surface area, this is because organic compounds with higher boiling points have covered the catalyst surface more than that of spent $B$ 
which results in the decrease of the specific surface area compared to fresh catalyst. The investigation also showed that the surface area became more opened on regeneration of the catalyst for both spent A\&B after chemical and thermal treatment burnt off some of the carbonaceous material deposited on the catalyst. This was clearly shown in the increment in the small, average and large surface area in addition, the high carbon deposits found on the deactivated catalyst were decreased after regeneration due to the burning off the coke (carbon) deposited on the catalyst. The progress and extent of regeneration were monitored using FTIR, SEM, XRD, GC-MS and XRF. The carbon content and effectiveness of the regenerated catalysts were determined and the values were compared with that of fresh catalysts. The regenerated catalysts showed $98-99.5 \%$ of the catalyst activity under the conditions of temperature and pressure of $500^{\circ} \mathrm{C}$ and 15 psi respectively.

This work has opened a window to refiners in undertaking in house assessment and troubleshooting of the catalytic reforming units which will ensure optimal operation of the units. It is recommended that refiners should regularly carryout such investigations on their units to ensure that optimal conditions for operations are employed.

\section{Acknowledgements}

The authors wish to acknowledge Ahmadu Bello University Zaria, National Research Institute for Chemical Technology Zaria and Kaduna Refining and Petrochemical Co. Ltd Kaduna for use of their facilities in the course of the work.

\section{References}

[1] Sinfelt, J. R., Anderson, J. R., Boudart, M.. (1981) Catalytic reforming of hydrocarbons. In Catalysis Science and Technology; Vol. 1, P.257.

[2] William C. B, Paul E. E, George J. B, Baton R, (1984) Catalyst regeneration in a catalytic reforming process. US patent 4440667.

[3] Beltramini, J. N. (1995) Regeneration of reforming catalyst. In Catalytic Naphtha Reforming; Marcel Dekker: New York, P. 365 .

[4] Weiszmann, J. A., Meyers, R. A., Ed.; 1986. Catalytic rereforming. In Handbook of Petroleum Refining Processes; McGraw-Hill: New York,; P.3-3.

[5] Antos, G.; Moser, M.; Lapinski, M, (2004); The new generation of commercial catalytic naphtha reforming catalysts. In: Prentice, Marcel Dekker: Catalytic Naphtha Reforming New York P. 335.

[6] Aguado, J, Serrano, J, Escola, J, and Briones, L, (2013) Deactivation and regeneration of $\mathrm{Ni}$ supported hierarchical Beta zeolite catalyst used in the hydroforming of oil produced by LDPE thermal cracking, Fuel, 109, 679.

[7] Xiao, Z; Laplante, A. R (2004) "Çharacterizing and recovering the platinum group materials-a review". Minerals Engineering 17. P. 9-10.
[8] Edgar, M. D. (1983), Catalytic reforming of naphtha in petroleum refineries. In Applied Industrial Catalysis; Leach, B. E., Ed.; Academic Press: New York; Vol. 1, P. 123.

[9] Gary, J. H. and Handwerk, G. E. (1984). Petroleum Refining Technology and Economics (2nd Edition ed.). Marcel Dekker, Inc. ISBN 0-8247-7150-8.

[10] Hafez Khiabani, N, Fathi, S, and Shokri, B ( 2015) Regeneration of naphta reforming catalyst 3using DBD plasma system $22^{\text {nd }}$ International Symposium on Plasma Chemistry, July 5-10, 2015; Antwerp, Belguim.

[11] Morris D. A and Calvinyl, B. (2015). Heterogeneous catalyst Deactivation and Regeneration:A Review. Catalysts 5(1), 145269 doi 10.3390catal 501045.

[12] Santosh, W and Sagar, K (2015). Catalyst Deactivation and Regeneration. International Journal of Scientific Engineering and Technology, Vol. No.4 Issue 105, 281-285.

[13] Rahimpour, M. R, Iranshahi D, Pourazadi E, and Bahmanpour, M. A, (2012) Boosting the gasoline octane number in thermally coupled naphta reforming heat exchanger reactor using de optimization technique, Fuel, 97, 109.

[14] Olori T. O (2015) Studies of Regeneration of Catalytic Reforming Catalyst (unpublished) MSc Research Thesis, Chem. Eng. Dept, Ahmadu Bello University Zaria.

[15] Axens Process Brochures for Octanizing and Aromizing Processes (2002); Axens IFP Group Technologies, RueilMalmaison, Paris, France.

[16] Mario, G, Courty, P, and Marcilly, C, (1997), Handbook of heterogeneous catalysis, edited by Eril, G, Knozinger, $\mathrm{H}$, and Weikamp, J (VCH, Weinheimi).

[17] Fung, S. C, (1994) Regenerating a reforming catalyst, Chemtech, 40.

[18] Clause, O. Dupraz, C. and Frank, J. (1998). Continuing innovation in catalytic reforming, presented at the NPRA Annual Meeting, San Antonio. March 1998.

[19] Gates, B. C.; Katzer, J. R.; Schuit, (1979) G. C. A. Reforming. In Chemistry of Catalytic Processes; McGraw-Hill: New York; P. 184.

[20] Pieck, C. L, Vera, C. R, Querini, C. A, Parera, J. M, (2005), Differences in coke burning off from Pt- $\mathrm{Sn} / \mathrm{Al}_{2} \mathrm{O}_{3}$ catalyst with oxygen or ozone. Applied Catalysis A: General 278, 173.

[21] Hosseini S. A, Aligholi N., and Dariush S. (2011). Production of $\gamma-\mathrm{Al}_{2} \mathrm{O}_{3}$ from Kaolin; Open Journal of Physical Chem., Vol 1, Pg 23-27.

[22] Bawa S. G, Ahmed A. S and Okonkwo P. C (2012) ' Thermal Transformation of Ammonium Alum Synthesized from Kankara Kaolin' Nigerian Society of Chemical Engineers Conference Proceedings 15-17 th Nov. p. 39-42.

[23] Yasuharu K., Takao K., Yoshio U. and Masatoshi S. (2005); Hydrodesulfurization of thiophene over Platinum supported on metal oxide catalysts. Muroran Institute of Technology. Pg 33-37.

[24] Karla S. K. (2009). Essentials of Refinery Processes; Indian Oil Corporation Ltd Panipat Refinery. (Cited online at petrofed. winwinhosting.net on June 25, (2014) by 11:00AM). 